\title{
"Na mais ilustre de todas as cidades, tão miserável tipografia": antiquariato, imprensa e epigrafia a partir de André de Resende (c. 1500-1573)
}

\author{
"In the most illustrious of all cities, so miserable a press": antiquarianism, \\ printing and epigraphy in André de Resende (c. 1500-1573)
}

\author{
Pedro Telles da Silveira \\ doca.silveira@gmail.com \\ Doutorando em História \\ Universidade Federal do Rio Grande do Sul \\ Rua General Vitorino, 72, apto. 93 - Centro \\ 90020-170 - Porto Alegre - Rio Grande do Sul \\ Brasil
}

\section{Resumo}

Este estudo procura compreender a relação entre a prática antiquária na Idade Moderna e a introdução da imprensa através do trabalho do humanista português André de Resende. Partindo tanto da história do livro quanto da história da historiografia, busca-se entender como a permanência dos manuscritos, as dificuldades técnicas relacionadas à impressão e as limitações dos próprios antiquários faziam um conjunto de circunstâncias técnicas se tornarem problemas teóricos. Procura-se, então, problematizar a distinção proposta pelo historiador italiano Arnaldo Momigliano entre fontes "literárias" e "não-literárias" através de uma atenção mais detalhada aos procedimentos de estudo e comunicação dos antiquários modernos.

\section{Palavras-chave}

Antiquariato; Imprensa; História da Historiografia.

\begin{abstract}
This article seeks to understand the relationship between antiquarian practice in Early Modern Europe and the introduction of printing technologies based on the work of the Portuguese humanist André de Resende. Drawing upon both the history of the book and the history of historiography, the article discusses how the permanence of handwritten texts, the technical difficulties related to the printing process and the limitations of the antiquarians themselves turned a set of technical circumstances into theoretical problems. Therefore, the distinction between "literary" and "non-literary" historical sources proposed by the Italian historian Arnaldo Momigliano is questioned through a detailed observation of the study and communicational procedures devised by modern antiquarians.
\end{abstract}

Keywords

Antiquarianism; Print; History of Historiography. 
De retorno a Portugal após um périplo que Ihe fez passar por Salamanca, Aix-en-Provence, Paris, Lovaina, Bolonha e Roma, o viajado homem de letras português André de Resende (c. 1500-1573) foi convidado para, no dia primeiro de outubro de 1534, proferir a oração de abertura do ano acadêmico da então Universidade de Lisboa. De claro pendor humanista, o erudito exorta seu auditório, em determinado momento, para aprender as letras gregas (RESENDE 1956 [1534], p. 39-41); ao cabo da oração, ele faz uma breve digressão sobre a etimologia do nome Lisboa, no qual o $n$ dobrado grego e o I desempenha um papel fundamental no asseverar se a cabeça do reino lusitano tem de fato Ulisses como seu fundador (RESENDE 1956 [1534], p. 57). Esta atenção às minúcias dos caracteres gregos - decisiva para um sólido julgamento filológico - representaria apenas o interesse erudito de Resende, caso o antiquário, na dedicatória que faz do volume ao monarca d. João III, não afirmasse também:

A instâncias de amigos e de uma boa parte de escolares, mandei de mau grado imprimir a oração de sapiência que há pouco fiz e pronunciei na Universidade de Lisboa, entre muitas outras razões, mormente porque a custo encontraria caracteres tipográficos adequados para esta matéria,

e, logo depois,

Entendi que devia mostrá-la a Vossa mui Augusta Majestade, não porque esteja persuadido de que a obra é digna de tal honra, mas porque eu, vosso protegido, e quantos professam as letras, temos esta obrigação perante Vós, que sois o maior professor das letras e seus cultores. $E$ também diga-se de passagem, para que, depois de verdes, na mais ilustre de todas as cidades, tão miserável tipografia, Vos apresseis a darnos a que tínheis resolvido, quando neste assunto Vos falamos (RESENDE 1956 [1534], p. 31; grifo meu).

"Na mais ilustre de todas as cidades, tão miserável tipografia". A dedicatória não deixa de ser também uma espécie de recriminação ao rei e um pedido a ele, que descuidou de sua função de patrono das letras. A trajetória desta reclamação, entretanto, não termina aí. O comentador moderno da obra confirma "o péssimo apetrechamento tipográfico" português da época, salientando que, em alguns exemplares da obra, aqueles caracteres gregos mencionados acima simplesmente não existem, tendo sido deixados em branco. Noutro exemplar, por sua vez, o próprio André de Resende teve de preencher estas lacunas à mão, desenhando os caracteres que faltavam (RESENDE 1956 [1534], p. 65, nota 2).

A passagem revela, portanto, que aos homens de letras que viviam em Portugal no começo do século XVI, a imprensa e a tipografia eram questões sensíveis para o avanço de suas iniciativas. Em obras dependentes de detalhes tão minuciosos, onde a ausência - por erro mecânico ou humano - de algum caractere, uma ilustração pouco fiel às intenções de seu autor ou uma edição malcuidada poderiam jogar em risco a credibilidade duramente construída de seu autor, como garantir a fidelidade na passagem dos manuscritos às obras impressas? No caso dos antiquários, a questão se tornava ainda mais premente, uma vez que a imprensa era utilizada para publicar e, por conseguinte, preservar anotações 
fugazes de objetos que, muitas vezes, estavam em vias de desaparecimento. Ao mesmo tempo, muitos eruditos se valiam dos novos recursos para efeitos que iam além da mera reprodução fidedigna de inscrições, monumentos e outras evidências materiais existentes, inserindo suas atividades nos domínios da falsificação e da invenção. Por fim, a própria desconfiança de muitos antiquários com relação à imprensa, para os quais ela era tanto um meio de difusão do conhecimento quanto um veículo para sua distorção, criava um campo de usos e possibilidades em tudo ambíguo no que toca às relações entre a erudição e as novas tecnologias da época. Em todas estas alternativas, os antiquários e eruditos do século XVI, em Portugal ou em outros lugares da Europa, estavam atentos aos aspectos técnicos envolvidos tanto na produção quanto na reprodução do passado que, muitas vezes literalmente, desenterravam.

Este trabalho tem por objetivo estudar o cruzamento entre a prática antiquária no século XVI e as preocupações com a imprensa, nesta mesma época, a partir do trabalho de André de Resende. Um primeiro momento deste estudo será dedicado ao entendimento da introdução da imprensa em Portugal e na Europa, as reações a ela por parte dos eruditos e, em especial, ao exame do tratamento de um tipo específico de evidência, o livro. Num segundo momento, nos voltaremos ao estudo da epigrafia por parte de Resende e outros antiquários da época, de modo a compreender a operação que ia da observação à anotação e da anotação à publicação. O olho, o manuscrito e o livro impresso, nesse sentido, participavam de um conjunto de procedimentos que, em suas constantes tensões, revela aspectos importantes do fazer antiquário quinhentista. O que unifica estas duas seções dedicadas a objetos bastante diferentes - o livro e as inscrições epigráficas - é a indagação a respeito do estatuto das fontes utilizadas pelo antiquário. Por isso, uma seção preliminar tem de ser dedicada ao trabalho do historiador italiano Arnaldo Momigliano.

\section{A natureza das fontes antiquárias}

Não é exagero afirmar que o moderno estudo do antiquariato começa com o artigo de Arnaldo Momigliano intitulado "Ancient History and the Antiquarian", publicado nas páginas do Journal of the Warburg and Courtauld Institutes em 1950. Trata-se, conforme Ingo Herklotz, de um texto que "ainda goza da esplêndida reputação não apenas de ter feito uma contribuição inovadora em seu próprio tempo mas também de permanecer fundamental para o estudo do antiquariato até o presente" (HERKLOTZ 2007, p. 127). As circunstâncias biográficas em torno à escrita deste artigo, o enraizamento de seu autor numa instituição privilegiada, o Warburg Institute, e a própria erudição do autor, aliada ao estilo de sua escrita (MILLER 2007, p. 6-7), levaram o artigo a ser lido como "a história do antiquariato cuja ausência o próprio Momigliano havia lamentado" (MILLER 2007, p. 12). E, apesar de textos críticos recentes (PHILLIPS 1996; WOMERSLEY 2006; HERKLOTZ 2007), ele não deixa de ainda caracterizar os termos do debate, inclusive desta presente contribuição.

Segundo Arnaldo Momigliano, o antiquário teria desempenhado importante papel na elaboração do moderno método histórico baseado na distinção entre 
fontes primárias e secundárias, ou em suas palavras, "autoridades originais e derivadas" (MOMIGLIANO 2014, p. 21). Para isso, o autor diferencia o historiador do antiquário a partir de uma série de oposições. Enquanto os historiadores escrevem em ordem cronológica buscando uma narrativa de viés moral, o antiquário se entrega à descrição sistemática e sincrônica do passado (MOMIGLIANO 2014, p. 22); enquanto os historiadores lidam com "fatos que servem para ilustrar ou explicar uma situação", os antiquários "coletam todos os itens que estão conectados a um determinado assunto seja para resolver um problema ou não" (MOMIGLIANO 2014, p. 22); por último, enquanto os historiadores se valem sobretudo de narrativas elaboradas por outros historiadores, utilizando-se de fontes "literárias", os antiquários se dedicam ao estudo de evidências materiais e de arquivo com as quais podem oferecer outra imagem do passado (MOMIGLIANO 2014, p. 22).

Para o historiador italiano, o conjunto de procedimentos que os antiquários desenvolveram a fim de tornar possível analisar este conjunto diversificado de fontes foi apropriado pelos historiadores na passagem do século XVII para o XVIII, quando uma série de ataques céticos vindos das fileiras do pirronismo buscavam colocar em xeque não apenas a utilidade mas a própria possibilidade do conhecimento histórico (MOMIGLIANO 2014, p. 30-31). O antiquário sai de cena, portanto, dotando o historiador de ferramentas capazes de tornar seu saber mais confiável: o método histórico.

O arco argumentativo proposto por Arnaldo Momigliano insere-se numa tentativa de compreender a relação entre a historiografia produzida na Idade Moderna e seus desdobramentos disciplinares a partir do século XIX, daí a importância dada ao método na apreciação do trabalho de antiquários, filólogos e eruditos. Essa não deixa de ser uma argumentação marcada por idiossincrasias e escolhas muito pessoais (MILLER 2007, p. 4; 27). Procura-se aqui contribuir com a discussão de algumas delas.

Dentre todas as oposições elencadas por Momigliano, a principal parece ser aquela entre fontes literárias e não-literárias. Ainda que um dos primeiros antiquários modernos, o italiano Flavio Biondo (1392-1463), tenha combinado "evidências literárias, arqueológicas e epigráficas, preferindo os textos literários e epigráficos" (MOMIGLIANO 2014, p. 25), a ênfase do autor na atividade dos eruditos dos séculos XVII e XVIII acaba por distorcer a relação entre estes variados tipos de fontes históricas (HERKLOTZ 2007, p. 136-137; 141). Nestes séculos, caracterizados pelo ceticismo, de acordo com Momigliano, "Assumiase que documentos e outras declarações públicas, moedas, inscrições e monumentos eram evidências mais qualificados que as fontes literárias" (MOMIGLIANO 2014, p. 32), diferenciando-se entre os textos recebidos pela tradição e aquelas "outras evidências tais como diplomas, inscrições, moedas e estátuas" (MOMIGLIANO 2014, p. 32). Os testemunhos materiais, portanto, possuiriam maior legitimidade que a palavra dos historiadores passados.

A caracterização das fontes "literárias" como o conjunto da tradição textual recebida, em oposição à categorização detalhada das espécies de evidências materiais, denuncia certa ausência de uma reflexão acerca da linguagem no 
entendimento das fontes históricas. Este problema é apenas tangenciado por Momigliano. Segundo o autor, houve, no decorrer destes séculos, dois padrões de sucesso, pois

Quando traçamos um panorama dos feitos dos antiquários em formular as regras da interpretação adequada da evidência não literária, precisamos fazer uma clara distinção. O sucesso foi completo no que toca ao estabelecimento de regras seguras para o uso de diplomas, inscrições e medalhas, tanto no campo da autenticação quanto no da interpretação (MOMIGLIANO 2014, p. 39).

Por outro lado, "Vasos, estátuas, relevos e pedras falavam uma língua muito mais difícil" (MOMIGLIANO 2014, p. 40). Em outras palavras, onde existia a possibilidade de uma via de acesso por meio do texto e da leitura, o conhecimento era possível; onde as evidências não possuíam uma referência textual, o conhecimento antiquário encontrava seu limite (VINE 2010, p. 135). Isso mostra que a importância das categorias de fontes "literárias" e "nãoliterárias", assim como a própria diferenciação entre elas, era muito mais fluida do que Momigliano parece admitir.

Para além destas considerações teóricas mais amplas acerca do papel da linguagem na avaliação das fontes antiquárias e na criação das próprias categorias de Momigliano, é interessante compreender os argumentos levantados por Ingo Herklotz em sua "resenha crítica" ao texto aqui trabalhado. Estes argumentos nos encaminham para os problemas técnicos que influenciavam as perspectivas teóricas dos antiquários modernos.

De acordo com Herklotz, a distinção entre fontes literárias e não-literárias não pode ser tomada como absoluta enquanto um dos critérios que definem, de um lado, o antiquário e, de outro, o historiador, porque "o apelo do antiquário por evidências não-literárias nunca foi um apelo por objetos materiais ao invés de, mas mais apropriadamente, em adição a fontes literárias" (HERKLOTZ 2007 , p. 137). O antiquário estudava a cultura material não porque as fontes escritas não eram confiáveis, mas sim porque elas não eram suficientes quando se tratava de propor uma imagem completa da antiguidade. Em segundo lugar, lembra o autor, havia uma série de considerações logísticas que guiavam o trabalho antiquário. Um estudioso na Alemanha, por exemplo, que decidisse estudar as antiguidades romanas necessariamente teria de fazê-lo - com exceção da escassa oferta de ruínas presentes em seu entorno - a partir de evidências de segunda mão (HERKLOTZ 2007, p. 137). Pode-se dizer que, ao articular esta distinção como um princípio metodológico e não como uma circunstância prática de pesquisa, Momigliano acaba por deixar de lado outros mecanismos da prática antiquária que também dependiam da visão, ainda que fosse de modo vicário e não direto: a correspondência, através da qual os antiquários podiam trocar descrições de ruínas, objetos e o conteúdo de documentos antigos (VINE 2010, p. 82-83; MILLER 2005); a circulação de livros e imagens tanto manuscritos quanto impressos que reproduziam estas mesmas evidências. Por último, a argumentação do historiador italiano pode acabar forçando a desviar a atenção 
de um conjunto de objetos que encontra um estatuto ambíguo nesta divisão, tais como os livros.

Esta avaliação do trabalho de Arnaldo Momigliano não tem por objetivo questionar o modelo proposto pelo autor, mas sim refletir a seu respeito para torná-lo produtivo a outras espécies de análise. Em aspectos gerais, ela aponta, através da reflexão acerca da diferença entre fontes literárias e não-literárias, para alguns dos aspectos que serão analisados nas páginas seguintes: o estatuto de evidências que não se enquadram facilmente em nenhuma das categorias acima; o papel retórico dos dispositivos textuais dedicados a gerar credibilidade dos trabalhos antiquários; a possibilidade de estudar fontes antiquárias sem o apoio de evidências textuais, o que levanta a dúvida a respeito de se os antiquários estavam realmente interessados - ou eram capacitados - em estudar estas evidências por sua materialidade ou se eles não as viam apenas como suportes para textos recém-descobertos. Nas páginas a seguir, traçaremos o caminho de André de Resende nestas idas e vindas entre a textualidade e a matéria.

\section{Livros, antiquários e tipógrafos}

Não é preciso muito esforço para compreender que a Renascença se inaugura com uma valorização do livro (PETTEGREE 2010, p. 10). A atividade de procura de manuscritos empreendida entre os séculos XIV e XVI proporcionou a recuperação de uma parcela significativa do legado clássico, ampliado o

60 conjunto de textos antigos disponíveis aos homens do Renascimento em comparação com o período imediatamente anterior. Petrarca, em 1333, descobriu o Pro Archia, de Cícero, e, em 1345, as cartas a Ático, do mesmo autor; em 1392, sob inspiração do chanceler florentino Coluccio Salutati, foram encontradas as epístolas ad familiares, também de Cícero; em 1416, Poggio Bracciolini descobriu o texto completo das Instituições Oratórias, de Quintiliano; cinco anos depois, o bispo Gerardo Landriani encontrou o manuscrito de cinco tratados ciceronianos, incluindo o texto completo do De Oratore (GRENDLER 1989, p. 120-121). Estes textos, novamente disponíveis para o público letrado, imediatamente se tornavam modelos de escrita e cultura para os então nascentes studia humanitatis.

Esse cenário não se modificou, apenas se intensificou, com a introdução da imprensa, embora o novo meio tenha sido recebido tanto com admiração quanto desconfiança. Nesse sentido, não teria sido necessariamente a invenção da imprensa que impulsionou o conjunto de transformações que associamos com o Renascimento e/ou a Idade Moderna, como sugere a conhecida tese de Elisabeth Eisenstein (1998), mas sim "as novas formas de educação e as mudanças na natureza dos governos", além da ativa promoção do estudo, sobretudo entre as elites, dos textos clássicos, que "criaram o novo público leitor laico da Renascença" (GRAFTON 1980, p. 274-275).

A vida de André de Resende se desenrolou sobre esse pano de fundo. Nascido por volta de 1500 em Évora, onde inicia sua educação com o gramático Estevão Cavaleiro, autor de obras pedagógicas humanistas, ele estuda entre 
1513 e 1521, com intervalos, em duas prestigiosas instituições universitárias espanholas, a recém-criada universidade de Alcalá de Henares e a tradicional universidade de Salamanca (MATOS 2000, p. XVIII-XIX). Entre outros motivos, a estada castelhana de André de Resende é importante por causa de dois acontecimentos editoriais. Primeiro, a produção da Bíblia Poligota, iniciativa do inquisidor-mor da Espanha, Jímenez de Cisneros, e que apresentaria o texto da Escritura em suas versões latina, grega e hebraica; o segundo foi a introdução, em 1516, das obras de Erasmo no reino castelhano, onde ele gozaria de grande favor até o final da década seguinte. Um dos canais de sua entrada na Espanha foi a Universidade de Alcalá, a mesma onde a Bíblia estava sendo editada, em especial pela atuação de seu chefe de impressões, Miguel de Eguía. Entre 1516 e 1524, trinta edições de obras de Erasmo seriam publicadas na Espanha, das quais 24 saíram de Alcalá (MOREIRA DE SÁ 1977, p. 7; BATAILLON 1966, p. 279-315; COROLEU 2008, p. 83-84).

É um pouco por influência do humanista neerlandês que Resende empreende sua viagem pela Europa. Primeiro se direcionando para a França, onde recebe as honras de subdiácono da ordem dominicana (MATOS 2000, p. XXIX), ele segue para os Países Baixos, onde se inscreve no Collegium Trilingue, de inspiração erasmiana, em 1529 (MATOS 2000, p. XXXIV). Na cidade belga, ele se corresponde com Erasmo, a quem envia um poema encomiástico, o qual foi encaminhado para publicação - sem que o soubesse - por este, tendo saído do prelo, também pela oficina de Frobenius, em 1530. Logo em seguida, Resende entra para o serviço de D. Fernando de Mascarenhas, embaixador português na corte de Carlos V, onde atua como professor de latim. Sob a tutela de Mascarenhas, Resende tem a oportunidade de viajar pelo Leste europeu e pela Itália, onde passa por Bolonha e Roma, antes de ser chamado novamente ao Reino lusitano.

O "péssimo apetrechamento tipográfico português", no dizer do comentador Artur Moreira de Sá, quando do retorno de André de Resende, se explica por motivos que não são atribuídos necessariamente ao suposto "atraso" luso com relação ao restante da Europa. A pequena população do Reino português e, por conseguinte, o reduzido público leitor, que não compensaria os gastos com a cara atividade de impressão, assim como o fato de que a grande maioria dos membros da corte portuguesa eram, ao menos, bilíngües, sendo versados em castelhano, quando não conheciam também o latim, língua literária por excelência da época, e a proximidade com a Espanha, por onde muitos dos livros entravam, são causas da timidez inicial dos esforços tipográficos lusitanos (MUSSER 2012, p. 115). Além disso, seria apenas por um curto período de tempo que o Reino lusitano, sob o reinado de D. João III, procuraria promover o português como linguagem científica europeia e, logo, sua imprensa própria, em especial através dos trabalhos do cosmógrafo Pedro Nunes (TARRío 2002, p. 82).

Em Portugal, as primeiras atividades tipográficas locais estiveram ligadas à impressão de obras litúrgicas judaicas no final da década de 1480; com a expulsão dos judeus em 1496, porém, esta incipiente atividade, a qual produzira obras de grande qualidade, fora encerrada (ANSELMO 1981, p. 26-27; MUSSER 2012, 
p. 113-114). Concomitante a esta atuação da comunidade judaica, em 1489 foi impresso o primeiro incunábulo latino em Portugal (MUSSER 2012, p. 114). Em Évora, cidade natal de André de Resende, a primeira oficina tipográfica a se instalar o fez somente em 1526 (MATOS 2000, p. XXVI). Entre as primeiras obras impressas portuguesas e a introdução da tipografia em Évora, entretanto, deve-se destacar a entrada dos impressores estrangeiros em Portugal, como o alemão Valentim Fernandes e o francês Germão Galharde (ANSELMO 1981; MUSSER 2012, p. 119120). Estes impressores e a circulação de livros através das fronteiras portuguesas garantem a ligação entre as correntes intelectuais europeias, principalmente aquelas relacionadas ao humanismo, e os desdobramentos mais específicos da atividade lusitana da época, como as navegações (LOPES 2012). Expansão do Império e expansão das letras, nesse sentido, eram também mediadas pela imprensa.

O trabalho dos homens de letras, no geral, acompanhou, como um de seus primeiros beneficiários e agentes, a introdução da imprensa. Muitos dos primeiros impressores eram humanistas e as primeiras iniciativas de fôlego no novo meio, muitas vezes, foram levadas a cabo por eruditos (PETTEGREE 2010, p. 70-71). O relacionamento entre humanistas e impressores, todavia, não era sempre tão harmonioso e, mais de um século após a introdução da imprensa, essas tensões alcançavam a relação entre o interesse mercadológico dos editores, as necessidades de defesa e afirmação dos Estados modernos e os diferentes graus com que a cortesania erudita era respeitada de local a local. Algumas passagens de André de Resende são ilustrativas desta situação.

Em carta escrita e publicada em 1567 endereçada ao erudito castelhano Bartolomeu de Quevedo, André de Resende critica seu colega toledano por se valer de textos clássicos que, embora pouco confiáveis, ganham repercussão pelo ar de novidade que trazem ao introduzir modificações que outras edições ou manuscritos não possuem:

Mas vieram agora a lume, segundo dizes, uns escólios a Ptolomeu que trazem alguns topônimos alterados, outros com esclarecimentos, e onde se lê: "Libora, outrora Élvora, hoje Talábriga, vulgo Talavera". Para que hás-de acreditar em escoliastas como esses que, baseados em informação de ignorantes e sem qualquer exame do local, e para agradarem aos tipógrafos (para que o livro se venda melhor), assim nos enganam? (RESENDE 1988 [1567], p. 101-103).

Escoliastas ávidos por reconhecimento e tipógrafos sedentos por rendas geravam sombras sobre a empresa erudita, e a passagem revela que as edições modernas de textos clássicos e outros trabalhos não necessariamente eram mais confiáveis que outras versões anteriores, que podiam circular manuscritas ou que, ao menos, receberam o devido cuidado quando foram enviadas à oficina de impressão. André de Resende faz eco, portanto, ao princípio de que o manuscrito, ao possuir uma difusão mais controlada, era mais veraz e fidedigno que a obra impressa (BOUZA 2001, p. 59; WOOD 1998, p. 87-88).

Estes casos também afetavam a rede de confiança por trás do empréstimo mútuo de manuscritos e outras obras efetuado não apenas pelos cortesãos mas 
sobretudo pelos letrados (BOUZA 2001, p. 48-49). Resende, na mesma carta a Quevedo, reporta ter sido alvo de um desses ataques:

Há já muito tempo que anseio por ler Juliano Pomério. Tanto mais que o vosso santo bispo Juliano, discípulo de Eugênio II, sucessor de Quirico, manifestou por ele grande admiração nos livros Dos prognósticos dos tempos vindouros, que compôs para Idálio de Barcelona. Estes livros, que me foram furtados há mais de vinte anos apor um hóspede parisiense, vim a recebê-los, um dia, impressos, mas sem terem sido devidamente expurgados dos erros que pululavam por todo o lado.

E a passagem seguinte demonstra que se trata - provavelmente - de casos recorrentes:

Vi um dia, na Alemanha, um opúsculo com os seus poemas, mas estavam em poder de um indivíduo que nem sequer por um dia mos quis emprestar (RESENDE 1988 [1567], p. 155).

Estas passagens confirmam que, apesar de algumas relações entre autor e impressor terem se tornado emblemáticas na época, como a que se desenvolveu entre Aldo Manuzio e o círculo europeu de letrados que se reunia em seu entorno em Veneza, ou aquela entre Erasmo e Frobenius na Basileia entre as décadas de 1510 e 1530, estas relações "pouco têm a ver com as oficinas de impressão que a maior parte dos cidadãos da República das Letras conhecia melhor" (GRAFTON 1980, p. 275). Nestes ambientes, não apenas os tipógrafos podiam agir de má-fé, visando apenas os lucros, como também os humanistas. Imersos em carreiras altamente competitivas, podiam utilizar a possibilidade de ampla circulação de ideias ocasionada pela imprensa para defender suas reputações atacando a de seus colegas, ou falsear livros e documentos para interesse próprio ou dos senhores aos quais estavam empregados, quando não eram apenas descuidados no manejo das provas ou queriam ver suas obras impressas o mais rapidamente possível, reproduzindo erros que se tornavam canônicos. Nestas circunstâncias, "não é surpreendente que muitos eruditos sentissem que a associação com o comércio tinha arruinado o que poderia ter sido a arte liberal da impressão" (GRAFTON 1980, p. 278).

Os casos relatados por Resende também indicam que muitas abordagens recentes da história da recuperação e da difusão do legado clássico, assim como dos comentários modernos à sua volta, acabam por subsumir os textos ao seu conteúdo, esquecendo que "o livro", nas cidades e cortes europeias, "não era apenas uma fonte de informação ou um repositório de conhecimento, mas um artefato apreciado e valorizado" (PETTEGREE 2010, p. 20; cf. também BOUZA 2001, p. 53). Justamente o valor associado ao livro enquanto objeto físico muitas vezes único fazia a cortesania letrada encontrar no empréstimo de manuscritos um de seus pontos de tensão.

Duas passagens da obra do humanista eborense, ainda em momentos avançados do século XVI, ajudam a ilustrar o valor associado ao livro. Na primeira, a abertura de seu diálogo publicado postumamente, o Aegidius Scallabitanus, 
cujo fio condutor é a vida do santo português frei Gil de Santarém, Resende retrata a si mesmo com um precioso "tesouro" em mãos:

[...] depois de regressar à minha cidade e de me instalar em casa, estava eu certo dia sentado no meu pórtico, por volta do meio-dia, a confrontar o dito livro [uma hagiografia do referido santo que o antiquário decide reescrever em melhor estilo] com a minha nova história, eis senão quando chega o médico Luís Pires, pessoa que, pela exuberância de sua erudição e pela afabilidade do seu trato, considero meu amigo e um indivíduo encantador. Começou por congratular-me com o meu regresso e depois, ao ver um livro velhíssimo, escrito em pergaminho e meio roído das traças, exclamou:

- Continuas igualzinho a ti mesmo, Resende! Ora diz-me lá: a que antro foste tu desenterrar tão vetusto achado?

- Ao dos frades, Pires - respondi.

- Algum tesouro deve ser, assim o espero - acrescentou ele. Porque os teus achados são sempre, é o teu costume, do mais requintado que há.

- Bem Ihe podes chamar tesouro. Mas se estás à espera de algum requinte, então ouve (RESENDE 2000, p. 294, grifos meus).

Já em seu opus magnus, as Antiguidades da Lusitânia, publicadas também postumamente, no ano de 1593, o antiquário português descreve a cena de estudo de um manuscrito antigo de Plínio, o Velho:

Há cerca de quarenta anos, quando eu estava a estudar em Salamanca, discuti muito com Fernando Pinciano, professor público de Grego e de Plínio, por causa do seguinte: mostrou-me um códice muito antigo com o texto de Plínio, que conseguira fazer vir, depois de dadas garantias, da Sé de Toledo para fazer a sua colação, e um outro não tão antigo, mas escrito com grande exatidão, da biblioteca da Universidade de Salamanca. Costumava abri-los diariamente, a hora certa, sob vigilância de dois guardas. Verificamos em ambos o que ele já demonstrara numa lição: que o copista, por descuido, tinha saltado, como logo me apercebi, cerca de dez ou doze linhas, que Plínio escrevera sobre o cabo Finisterra para o passo em que descreve o cabo da Roca, do que resulta grande confusão e mesmo uma deturpação do próprio Plínio (RESENDE 1996 [1593], p. 75, grifos meus).

Em ambos os casos, o valor associado ao livro é dado tanto por seu conteúdo quanto por sua situação material: no primeiro caso, o conteúdo, embora altamente informativo, é de menor valor dado seu estilo rude, mas o que Ihe garante o estatuto de "achado" é a sua antiguidade; na segunda situação, as diferentes versões de um mesmo texto, criadas com um grande intervalo de tempo entre si, transformam os manuscritos em instrumentos de trabalho. A segunda passagem também revela o cuidado associado com o transporte, o empréstimo e o manuseio de manuscritos entre uma instituição - a Sé de Toledo - e outra, a Universidade de Salamanca.

Um segundo aspecto que se abre a ser estudado a partir desta última passagem é a própria variação entre um manuscrito contendo os textos clássicos e outro, os quais estavam longe de possuir versões integralmente estabilizadas. Como já vimos, era através da atenção às minúcias que o trabalho de erudição era feito. As Antiguidades da Lusitânia, novamente, possuem certo número de 
passagens que ilustram este problema. Ao discorrer a respeito de se os vetões e os vectões são ou não o mesmo povo, Resende lamenta não poder ter apreciado "este passo de Políbio [...] além dos cinco livros escritos em Grego e vertidos para Latim por Nicolau Perotto, arcebispo de Macedônia, nenhuma outra edição atual me foi dado encontrar" (RESENDE 1996 [1593], p. 83; grifo meu). Logo depois, ele deixa sua conclusão em suspenso, pois "embora seja bem evidente pelo diverso testemunho dos autores e pela diferença de grafia de uma só letra", ele não pode consultar "Estrabão, em cujos códices, que parecem brincar estranhamente com este nome, não sei se por culpa dele ou dos copistas, ora são Ovetões, depois Vuetões e logo Oveciões" (RESENDE 1996 [1593], p. 85; grifo meu). Manuscritos corrompidos e edições defeituosas dificultavam o trabalho do antiquário, de modo que a tarefa da erudição era não apenas purificar o latim escrito em seu século (RESENDE 1996 [1593], p. 57) mas também corrigir os textos então em circulação:

Compreendemos assim claramente que não estariam muito distantes [os pesuros, outro povo limítrofe aos lusos na Antiguidade] daquele lugar e ao mesmo tempo que o seu nome devia ser emendado, passando da segunda para a terceira declinação nos manuscritos de Plínio (RESENDE 1996 [1593], p. 91, grifo meu).

Os textos clássicos - as fontes literárias - não eram unívocos e podiam ser modificados pelo influxo da argumentação do próprio erudito, através da comparação com outros manuscritos ou com outras espécies de evidência, mormente as epigráficas. Na verdade, eles pouco eram textos mas sim edições, volumes, códices e manuscritos, ou seja, objetos variáveis que apontavam tanto para si mesmos quanto para o conteúdo que continham. As passagens acima também mostram que o antiquário se aproximava de suas fontes atuando como um filólogo (HERKLOTZ 2007, p. 131-132), procedendo por cotejamento com vistas à emenda dos textos antigos. Seu procedimento de trabalho, portanto, tinha maior sucesso quando havia exemplares entre os quais comparar. Nas situações onde os exemplares não existiam ou estavam indisponíveis, como na primeira hagiografia de frei Gil ou nas edições defeituosas citadas por Resende, os antiquários ou tinham de deixar suas questões em aberto ou recorrer à conjectura para conseguir estudar os textos. Estes problemas, logo veremos, se tornavam mais agudos no caso das inscrições epigráficas.

Estes exemplos mostram que a distinção entre fontes literárias e nãoliterárias não era tanto um princípio metodológico quanto uma circunstância da pesquisa (HERKLOTZ 2007, p. 136-137). Quando estavam disponíveis exemplares diferentes de um mesmo texto, diferenças materiais entre uma versão e outra eram ressaltadas. Isso também indicava o efeito de uniformização causado pela imprensa, cujas edições principes se tornavam o padrão, por mais defeituosas que fossem, para a análise dos manuscritos por eruditos do continente inteiro. Até mesmo para um antiquário trabalhando numa região menos marginal do Império romano como era a Lusitânia, por mais que as evidências "não-literárias" fossem buscadas, as fontes "literárias" eram, ao 
cabo, incontornáveis e, no fim, ambas se confundiam. Como afirma André de Resende perto do abrupto fim de suas Antiguidades da Lusitânia, ele não se propôs enumerar todas as cidades do Portugal moderno e o seu correspondente antigo, "mas tão-só aquelas que ou foram nomeadas pelos escritores antigos ou que, graças a velhas inscrições ou a um feito muito notável, tornaram em qualquer lado e por seu mérito os nomes conhecidos" (RESENDE 1996 [1593], p. 194). Ou seja, o que não estava escrito não podia ser estudado.

\section{Imprensa e epigrafia}

"O renovado interesse no mundo clássico no Quatrocentos", afirma Lucia A. Ciapponi, "trouxe uma mudança no gosto que afetou toda atividade cultural" (CIAPPONI 1979, p. 18), e isso não apenas no limitado campo da caligrafia que a autora estuda, mas sobretudo na educação, na política, na estética e, claro, no estudo histórico e antiquário. Pode-se dizer, com isso, que a era dos antiquários não representou apenas "uma revolução no método histórico", mas também uma "revolução no gosto" pela Antiguidade clássica, invertendo-se a ênfase da formulação de Arnaldo Momigliano (MOMIGLIANO 2014, p. 20). Era o interesse renovado pelo mundo clássico que tornava possível estabelecer novas espécies de evidências para estudá-lo.

Uma breve anedota contada a respeito de André de Resende pelo editor das Antiguidades da Lusitânia, o também eborense Diogo de Vasconcelos, ajuda a compreender esta situação. Segundo o editor, Resende, de retorno a Portugal, passou a se dedicar com tamanho afinco à tarefa de decorar sua residência com "antigos mármores" e "inscrições romanas" que

[...] todas as vezes que ia de viagem, muito embora partisse para lugares bem longe, tinha sempre o cuidado de levar dentro da bagagem uma enxada e outras ferramentas, para que, se the aparecessem nalgum sítio vestígios da antiguidade, os pudesse mandar escavar, pagando do seu próprio bolso e por sua iniciativa, para os dar a conhecer aos seus habitantes (RESENDE 1996 [1593], p. 55).

Ou seja, no cotidiano do antiquário, as evidências materiais eram simultaneamente meios para se obter uma imagem mais completa do passado e objetos que serviam para atender ao gosto classicizante da época. Ainda assim, se Resende apreciava esteticamente os vestígios do passado, não parece claro que ele tinha os instrumentos para abordar os aspectos mais propriamente "artísticos" e materiais destas evidências em sua atuação enquanto antiquário.

O caso das inscrições epigráficas se torna especialmente significativo, pois elas combinam de maneira única e indissociável a materialidade do objeto histórico e a legibilidade do texto antigo. Como bem sintetiza André de Resende em sua História da Antiguidade da Cidade de Évora, trata-se de "escrituras de pedra" (RESENDE 1963 [1553], p. 14), ou, noutro momento, na epístola a Bartolomeu de Quevedo, quando afirma mais explicitamente: as inscrições são "pedras falantes" (RESENDE 1988 [1567], p. 123). Estas pedras que falam se prestam a ser lidas porque "ou mantêm intacto ou morrem ao mesmo tempo que as letras nelas 
gravadas" (RESENDE 1996 [1593], p. 58). Conteúdo e suporte, nas inscrições epigráficas, são uma e mesma coisa; as declarações de Resende, no entanto, mostram que as inscrições parecem interessar mais pelo conteúdo escrito do que pelos elementos gráficos que as cercavam e, no fim, as constituíam.

Essa será uma dificuldade apenas ocasionalmente superada na história dos estudos epigráficos ao longo dos séculos XV e XVI. Como sugere William Stenhouse, os dois caminhos já estavam presentes em Poggio Bracciolini (13801459) e Ciríaco de Ancona (1391-c.1435), pioneiros no estudo das escritas talhadas em pedras. Enquanto o primeiro se ocupava do estudo dos textos e do que elas poderiam revelar de novo acerca da história antiga, o segundo, talvez pelas deficiências de seu conhecimento linguístico, tendo aprendido latim apenas em sua maturidade, se interessava mais pela estrutura física, a qual reproduzia em desenhos de variado detalhamento (STENHOUSE 2005, p. 22). No caso de Ciríaco de Ancona, mercador e diplomata que entrara em contato com as inscrições em suas muitas viagens ao Oriente, a atenção aos detalhes físicos também se explica pelo fato de que a maior parte das inscrições que copiava eram em grego, o que, dado o relativo desconhecimento do idioma, dava margens menores para a interpretação.

Ainda segundo Stenhouse, talvez o mais importante epigrafista da segunda metade do século XV tenha sido Fra Giovanni Giocondo (1433-1515). Giocondo teria sido um dos primeiros a aplicar os conhecimentos da filologia ao estudo das inscrições, organizando o corpus epigráfico em famílias de inscrições de acordo com sua origem e distinguindo entre as evidências que ele mesmo vira e, outras, que soubera por meio de terceiros, como, por exemplo, outras coleções epigráficas (STENHOUSE 2005, p. 24). Ele também se interessava pelos aspectos gráficos das inscrições, em especial pela forma das letras e pela qualidade do entalhamento, através de cuja análise ele poderia datar em que momento da história romana elas foram feitas (STENHOUSE 2005, p. 25). Essas preocupações devem ser pensadas em conjunto com sua atuação nos círculos ligados ao pintor Andrea Mantegna (c. 1431-1506); por volta da metade do século $\mathrm{XV}$, o artista florentino começara a incorporar o texto e a caligrafia das inscrições em seus trabalhos, de modo que o estudo da materialidade das inscrições também servia para reforçar a legitimidade e a ambientação clássica de seus próprios quadros (CIAPPONI 1979, p. 23). ${ }^{1}$

Apesar das iniciativas de Giovanni Giocondo, a aproximação entre artistas e eruditos continuaria apenas esporádica. Como admite o próprio Stenhouse ao reconhecer que a segunda inovação de Giocondo - o estudo das condições de feitura das inscrições e de suas características físicas - teria fortuna consideravelmente menor que seu primeiro insight, o qual aproximava o estudo

\footnotetext{
${ }^{1}$ Algo semelhante se aplica ao relacionamento entre André de Resende e Francisco de Holanda explorado, em variadas publicações, por Sylvie Deswarte-Rosa. Com profundo interesse antiquário, o retratista e tratadista Holanda, mais jovem que Resende, recebeu deste educação na composição epigráfica; ambos se aproveitavam de seus conhecimentos para forjar inscrições que eram então "descobertas", diz a autora, quando a corte estava reunida, para grande efeito (DESWARTE-ROSA 2008, p. 282-283). Que pouco deste conhecimento do como fazer as inscrições, necessário para criar falsificações bem-sucedidas, transpareça no trabalho antiquário de Resende é mostra do distanciamento que estamos propondo aqui.
} 
epigráfico das técnicas já disponíveis para a avaliação de manuscritos antigos (STENHOUSE p. 25). O surgimento da imprensa e, com ela, o desenvolvimento das técnicas da xilogravura e da gravura em metal, não mudaria este cenário (WOOD 1998, p. 85) - e isso por causa dos objetivos e métodos dos próprios antiquários. Este cenário somente sofreria mudanças significativas a partir da segunda metade do século XVI, quando antiquários, compiladores e patronos como Onofrio Panvinio, Jean Matal e Antonio Agustín passariam a levar em consideração as características físicas das inscrições para inclui-las num quadro ampiado da história romana (STENHOUSE 2005, p. 43 e ss.). Esta é uma mudança da qual, entretanto, tanto André de Resende como outros antiquários e epigrafistas portugueses não parecem ter participado (ALMAGRO 2008).

As inscrições normalmente eram reunidas em coletâneas, os chamados syllogai, que circulavam em forma manuscrita. Segundo Christopher S. Wood, uma série de motivos presidiam a decisão por mantê-los em forma manuscrita. Em primeiro lugar, a base de leitores dos syllogai era muito pequena, não justificando os custos da impressão (WOOD 1998, p. 88). Livros a respeito de temas eruditos, como se sabe, eram notoriamente difíceis de serem compostos. Comentários exigiam repensar a distribuição do texto na página; volumes que abordavam as tradições grega ou hebraica necessitavam do desenvolvimento de caracteres tipográficos próprios; obras que dependiam de material visual tinham de contar com o desenvolvimento das técnicas de gravura para recriá-las fielmente. Algumas destas iniciativas foram realizadas, já em meados do Quinhentos, com esmerado empenho, como as coleções numismáticas de Guillaume Rouillé, Promptuaire de médailles, e o Epithome du thrésor des Antiquitez, de Jacopo Strada, ambos de 1533, e os Discorsi sopra le medaglie de gli antichi, de Enea Vico, publicado em 1555 (HASKELL 1993, p. 14-16), para não mencionar, no campo da epigrafia, a pequena coletânea que reproduzia vinte e duas inscrições realizadas sob direção de Conrad Peutinger em 1505 (WOOD 1998). Os motivos para imprimir tinham mais a ver com a tentativa de alcançar um público maior, especialmente para eruditos baseados em localidades periféricas da República das Letras europeia naquele momento, do que com a busca de fidelidade na reprodução das evidências materiais (WOOD 1998, p. 84). Isso também mostra, como veremos em maior detalhe nos procedimentos de trabalho de André de Resende, que, no mundo dos antiquários, o contato pessoal e a correspondência continuaram sendo meios privilegiados para o estabelecimento das redes de contato muito tempo após a introdução da tipografia.

Um segundo motivo, por sua vez, possui relação direta com estas últimas considerações. Os syllogai eram vistos como empresas colaborativas e o próprio conceito de autor de uma coletânea de inscrições era problemático (WOOD 1998, p. 88); quando impressas, elas recebiam o nome do impressor (WOOD 2001, p. 113) ou do patrono que as encomendara (STENHOUSE 2005, p. 45-46). Um exemplo destas coletâneas manuscritas que circularam pela Europa, articulando uma ampla de rede de colaboradores mas sem chegar à imprensa, é a de Mariangelo Accursio (c. 1490-c. 1546), que no primeiro quarto do século XVI perambulou pelo continente europeu, chegando até 
Portugal, com o objetivo de anotar todas as inscrições disponíveis em sua época (DESWARTE-ROSA 2012a) - ou seja, um equivalente renascentista do Corpus Inscriptionum Latinum.

Manuscritas ou impressas, as inscrições também variavam consideravelmente de acordo com o talento - ou a falta de talento - de quem as copiava. Variações na caligrafia, que poderiam ajudar a datar as inscrições ou a quebra das linhas, elementos que auxiliavam na compreensão do uso do espaço na superfície das rochas inscritas e, por conseguinte, na ênfase e nos modos de leitura das frases nelas gravadas, dificilmente eram reproduzidas (WOOD 1998, p. 87). No ambiente altamente competitivo dos círculos eruditos do Quatrocentos e Quinhentos, as abreviações e as ligaduras presentes nas inscrições normalmente eram desdobradas (STENHOUSE 2005, p. 47); elas ofereciam, assim, aos antiquários uma oportunidade de demonstrar seu "gênio" pessoal ao transformar as alquebradas inscrições epigráficas em prístinas peças de discurso. O interesse pelas características físicas dos cipos, frisos, degraus de escadas, colunas, marcos miliários e ruínas onde as inscrições se encontravam parece surgir apenas ocasionalmente de acordo com os interesses do erudito que as estuda, e não como uma etapa da investigação necessária a sua compreensão. O fato de que eram únicas impunha a necessidade de revêlas para que pudessem ser comparadas, o que era dificultado pela própria perda de inscrições com as constantes renovações urbanas da época quanto pelo grande número de falsificações (WOOD 2001, p. 99). Por todos estes motivos, as inscrições eram estudadas sobretudo por seu seu conteúdo linguístico e, nesse contexto, a introdução da imprensa era vista como um obstáculo adicional entre a observação, a anotação e a leitura, e não como uma solução para sua fiel reprodução.

Um exemplo pode ser encontrado na epístola de André de Resende endereçada a Bartolomeu de Quevedo, que já tivemos a oportunidade de conhecer antes. A data de escrita e publicação - 1567 - demonstra que estes problemas persistiam mesmo com o correr do século. Ao discutir a respeito dos limites da província romana da Lusitânia em comparação com o território do reino de Portugal, Resende afirma:

Tenho em minha casa um enorme cipo de mármore, a que faz referência o reverendo senhor que atualmente é bispo de Osma, na sua obra Das várias resoluções. O cipo diz o seguinte (só não tive oportunidade de reproduzir, por falta de caracteres tipográficos adequados, os nexos das letras que se sobrepõem umas às outras para economizar espaço) (RESENDE 1988 [1567], p. 137).

Ao que se segue a reprodução, de página inteira, da referida inscrição. 
Figura 1 - Inscrição apresentada na carta a Bartolomeu de Quevedo, reproduzida aqui a partir da primeira edição contida no volume Carmen Endecassylabon (Lisboa, 1567)

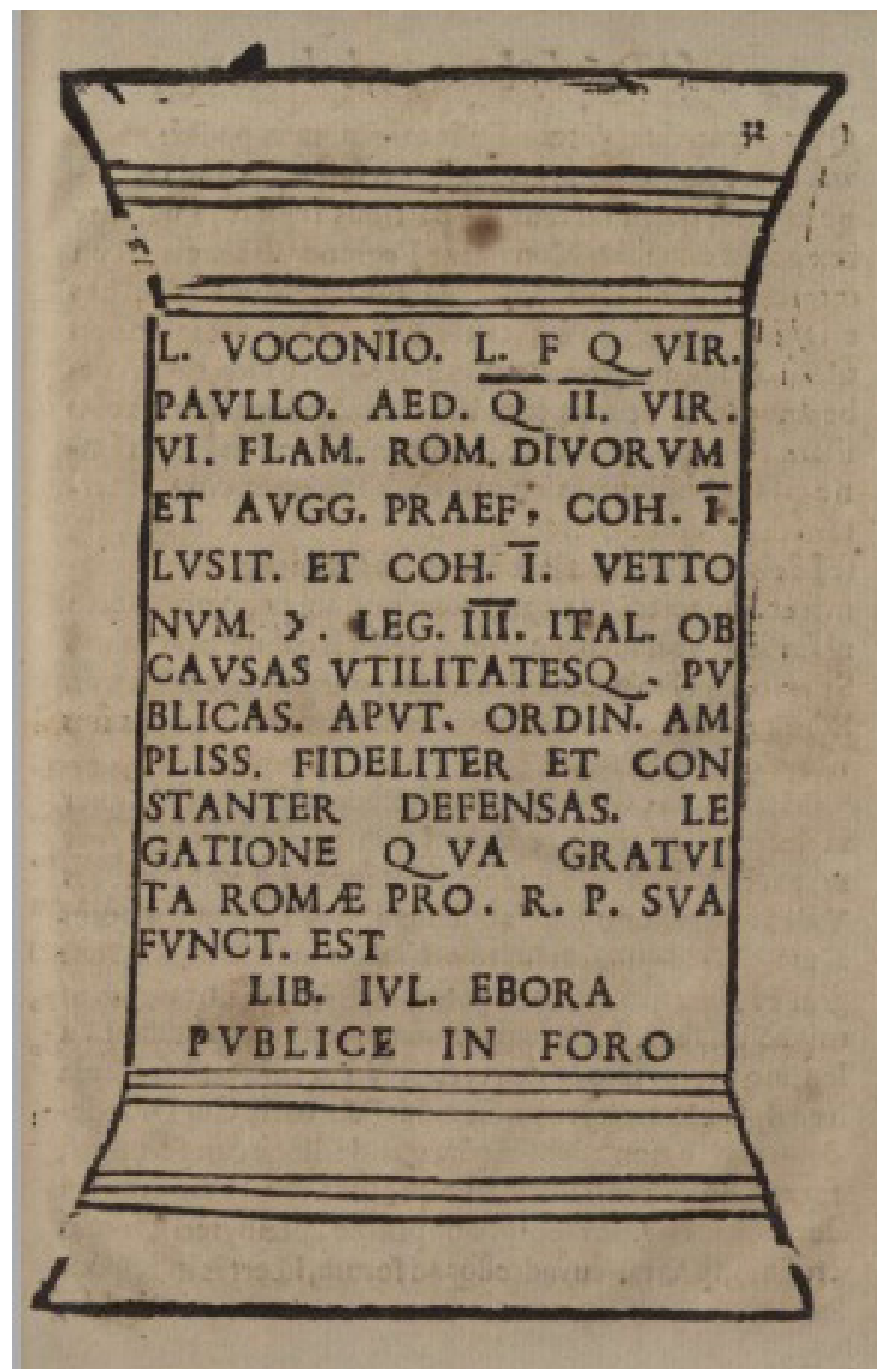

Este exemplo ainda é excepcional porque mostra a atenção de Resende à forma das letras; esta atenção, todavia, não serve para motivos de datação ou entendimento das circunstâncias em que a evidência fora constituída (STENHOUSE 2005, p. 54), e se reduz à avaliação do grau de dificuldade de sua leitura. Ela acaba por revelar o limite técnico alcançado pelas práticas mais cotidianas da imprensa em meados do Quinhentos, as quais eram normalmente incapazes de reproduzir graficamente a materialidade das inscrições. A passagem confirma, portanto, a declaração de Christopher S. Wood segundo a qual se a imprensa causou algum efeito no estudo epigráfico, foi o de ter acelerado "a divisão entre a ilustração erudita e a ilustração decorativa" (WOOD 2001, p. 105).

Observando-se outros exemplos de inscrições representadas em obras de André de Resende, percebe-se que eles são apresentados de forma bastante 
esquemática, muitas vezes trocando-se apenas o texto aplicado sobre um mesmo modelo, em outros casos retirando-se toda a referência à materialidade do objeto (tal como o desenho dos contornos) para apresentar somente as letras. A incapacidade técnica de render a unicidade de cada inscrição acabava por dissociar conteúdo e suporte - o qual era meramente descrito no texto do autor - e transformava uma evidência visual numa evidência textual. Nesse caso, a passagem preconizada por Arnaldo Momigliano do estudo das fontes textuais para as fontes materiais não era necessariamente resultado de uma decisão metodológica, mas de uma falha técnica.

Figuras 2 e 3 - Exemplos de inscrições retirados da primeira edição das Antiguidades da Lusitânia (1593)

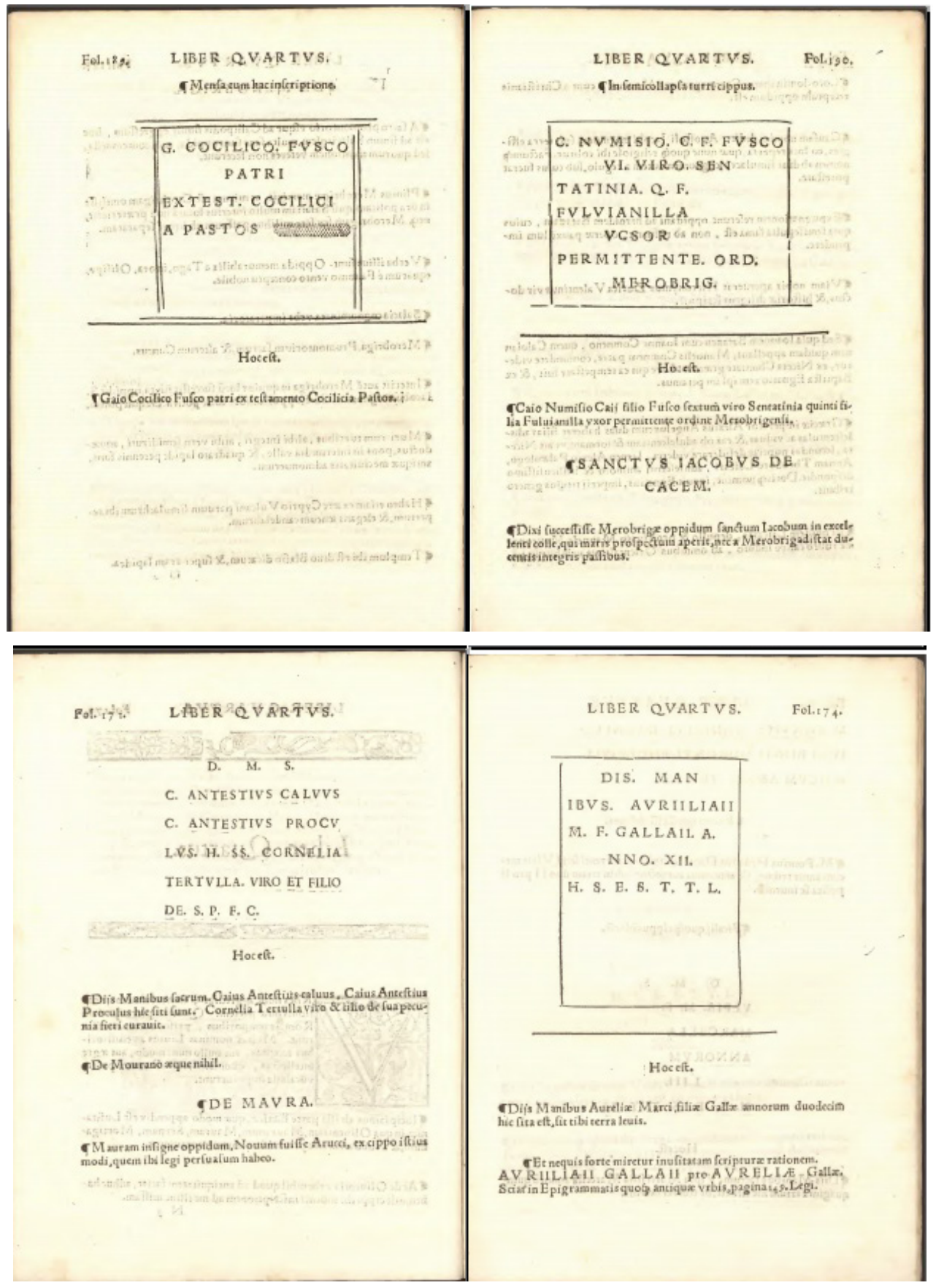


Além disso, outras séries de preocupações se somavam à representação das inscrições epigráficas. De um lado, os interesses dos editores, que, buscando reduzir os custos da impressão, escolhiam molduras simples para baratear os gastos com as provas e procuravam posicionar o maior número possível de caracteres na página de modo a aproveitar o espaço da folha (WOOD 1998, p. 99 e ss.). De outro lado, as próprias funções retóricas destes recursos gráficos, ainda que simples ou justamente porque eram simples. As quatro linhas da moldura que cercavam as inscrições reproduzidas na página e as letras, sempre grafadas em maiúsculas, eram uma convenção estilística que sinalizava a representação das inscrições e desviava a atenção de outros aspectos da materialidade das mesmas que, por não serem passíveis de reprodução, a apresentação defeituosa poderia ser tomada como um ato de má-fé. Importava mais, nesse sentido, submeterse às convenções em torno à forma de apresentação das inscrições do que dar indicações precisas acerca de sua constituição ou do local onde pudessem ser encontradas para serem verificadas por outros eruditos - e, importa lembrar, muitas inscrições nunca existiram fora das páginas, manuscritas ou impressas, das coletâneas antiquárias, de modo que o próprio caráter vago da apresentação servia para sustentar a pretensa autenticidade de evidências espúrias (WOOD 2001, p. 109).

Com isso, podemos percorrer no caminho inverso o trabalho antiquário, partindo de seu produto final - um livro ou uma coletânea, por exemplo - em direção a seus procedimentos de trabalho, onde, novamente, não houve uma simples transição do manuscrito ao impresso, mas um complexo jogo de idas e vindas entre os dois. Embora tenhamos poucos registros do método de trabalho de André de Resende, a complicada história de sua obra mais conhecida, as Antiguidades da Lusitânia, nos permite ter um vislumbre de como ele atuava.

Quando faleceu em 1573, André de Resende organizara apenas parte do texto para publicação. Suas anotações e sua biblioteca foram inventariadas logo após sua morte, todavia o trabalho no livro só foi retomado na década de 1580, sob insistência do monarca Filipe II, que designou o editor Diogo Mendes de Vasconcelos para completar a obra (RESENDE 1996 [1593], p. 61). O editor pinta um quadro um tanto quanto caótico do estado da obra quando passou a dela se ocupar. $O$ antiquário eborense deixara preparados apenas quatro dos dez livros que se propunha escrever (a obra foi editada com quatro livros mais uma parte suplementar a respeito de Évora, composta por Vasconcelos). Os cadernos de Resende, entretanto, "ficaram tão cheios de rasuras e apagados com asteriscos e obeliscos, que cheguei a suspeitar estar à mão com tarefa sem solução" (RESENDE 1996 [1593], p. 60). Além disso, Resende deixara as inscrições "totalmente dispersas e confundidas por várias folhas, num só códice" (RESENDE 1996 [1593], p. 60). Para Vasconcelos, o motivo pelo qual o antiquário tinha assim procedido talvez seja que não lhe "sobrara tempo para as transcrever e para as por em ordem, a um homem que sem parar trabalhava em todo o gênero de coisas literárias", 
ou porque, a fim de ter notícias exata das antiguidades e devido à sua extraordinária memória, só ficava satisfeito com as folhas originais, que Ihe fossem mandadas de toda a parte, embora mal copiadas e corrompidas (RESENDE 1996 [1593], p. 61, grifo meu).

Ou seja, o manuscrito tinha um papel preponderante no trabalho antiquário, não apenas no que toca aos rascunhos preparados para impressão, mas também nas anotações das evidências que encontrava e na circulação destas evidências, como atesta o caso das inscrições anotadas por Resende e também das enviadas a ele. Como destaca Angus Vine, "uma história do antiquário deve ser também uma história de seu círculo e de seus correspondentes" (VINE 2010, p. 82). Esta comunicação é que Diogo de Vasconcelos considera tão difícil de reduzir ao formato de livro, praticamente reescrevendo a obra de Resende.

Embora as referências acima situem o manuscrito quase que apenas em relação ao impresso, é possível ver como a circulação manuscrita era relevante para o antiquário. Em especial, ele coloca um problema que pode passar da esfera técnica à esfera teórica. Como um das passagens acima afirma, André de Resende dependia de muitas anotações que Ihe eram enviadas, com diferentes graus de fidelidade. Trazendo-se a discussão para o contexto em que Arnaldo Momigliano a trata, pode-se pensar na anotação desmaterializando uma evidência material para depos recriá-la sob a forma, primeiro, da anotação e, posteriormente, da edição impressa (WOOD 2001, p. 95). Sendo assim, mesmo as evidências materiais, ainda que fossem vistas à primeira mão, se estabeleciam numa relação mediada pela escrita. Como afirma, novamente, Angus Vine, "a preservação do passado se transforma numa empresa tanto literária quanto histórica" (VINE 2010, p. 83).

Tendo isso em vista, podemos considerar que os antiquários e eruditos da Idade Moderna não participavam apenas de uma cultura letrada - a República das Letras - centrada em si mesma tampouco ascendiam por seu status de autor, todas estas prefigurações de um ambiente acadêmico que somente surgirá muito posteriormente. Talvez seja necessário pensar que os antiquários e eruditos participavam também de uma cultura escrita, onde as inscrições que estudam demonstram sua atenção às escritas expostas, onde a comunicação não se dá apenas com seus pares mas também com pessoas de maior ou menor grau social que compartilham o interesse pelas evidências históricas, onde estudar o passado não significa estar apartado das preocupações - bastante materiais e pragmáticas - do mercado dos livros e do trato com editores e impressores e onde, por fim, a construção das evidências históricas estava sujeita não apenas a imperativos teóricos como também a injunções relativas à técnica e ao trato pessoal entre antiquários, eruditos, impressores e o público à sua volta.

\section{Referências bibliográficas}

ALMAGRO, Alejandra Guzmán. A Portuguese Contribution to 16th Century Roman Antiquarianism: The Case of Aquiles Estaço (1524-1581) and Roman Epigraphy. In: BERBARA, Maria; ENENKEL, Karl A. E. (eds.). Portuguese Humanism and the Republic of Letters. Leiden: Brill, 2012, p. 353-373. 
ANSELMO, Artur. Origens da imprensa em Portugal. Lisboa: Imprensa Nacional/Casa da Moeda, 1981.

BATAILLON, Marcel. Erasmo y España. Estudios sobre la historia espiritual del siglo xvi. Mexico, D.F.; Buenos Aires: Fondo de Cultura Económica, 1966.

BOUZA, Fernando. Corre manuscrito: una historia cultural del Siglo de Oro. Alvarez: Marcial Pons, 2001.

CIAPPONI, Lucia A. A Fragmentary Treatise on Epigraphic Alphabets by Fra Giocondo da Verona. Renaissance Quarterly, v. 32, n. 1, p. 18-40, 1979.

COROLEU, Alejandro. Anti-Erasmianism in Spain. In: RUMMEL, Erika (org.). Humanism and Scholasticism in the Age of Erasmus. Leiden: Brill, 2008, p. 73-92.

DESWARTE-ROSA, Sylvie. Le voyage épigraphique de Mariangelo Accursio au Portugal, printemps 1527. In: BERBARA, Maria; ENENKEL, Karl A. E. (eds.). Portuguese Humanism and the Republic of Letters. Leiden: Brill, 2012, p. 19-111.

. O ramo de ouro do saber. F. Olandius. Apoloni Dicauit. In: MORAES, Luiz (org.). A Fábrica do Antigo. Campinas: Ed. UNICAMP, 2008, p. 269-292.

EISENSTEIN, Elisabeth. A revolução da cultura impressa: os primórdios da Europa moderna. São Paulo: Ática, 1998.

GRENDLER, Paul F. Schooling in the Renaissance Italy. Literacy and Learning, 1300-1600. Baltimore: The Johns Hopkins University Press, 1989.

GRAFTON, Anthony. The Importance of Being Printed. Journal of Interdisciplinary History, v. 11, n. 2, p. 265-286, 1980.

HASKELL, Francis. History and its images: art and the interpretation of the past. New Haven: Yale University Press, 1993.

HERKLOTZ, Ingo. Momigliano's 'Ancient History and the Antiquarian': A Critical Review. In: MILLER, Peter N. (ed.). Momigliano and Antiquarianism: Foundations of the Modern Cultural Sciences. Toronto: Toronto University Press, 2007, p. 127-153.

LOPES, Marília dos Santos. From Discovery to Knowledge: Portuguese Maritime Navigation and German Humanism. In: BERBARA, Maria; ENENKEL, Karl A. E. (eds.). Portuguese Humanism and the Republic of Letters. Leiden: Brill, 2012, p. 425-445.

MATOS, Manuel Cadafaz de. André de Resende (c. 1500-1573), o homem e a obra: um contributo para a sistematização dos seus trabalhos impressos até 1551. No quinto centenário do nascimento de um humanista erasmiano. In: Algumas obras de André de Resende: 1531-1551. Lisboa: Câmara Municipal de Évora, 2000, v. 1, p. VII-XCVI.

MILLER, Peter N. "Introduction: Momigliano, Antiquarianism, and the Cultural Sciences", in MILLER, Peter N. (org.). Momigliano and Antiquarianism: 
Foundations of the Modern Cultural Sciences. Toronto: Toronto University Press, 2007, p. 3-65.

MOMIGLIANO, Arnaldo. História antiga e o antiquário. Anos 90, v. 21, n. 39, julho de 2014, p. 19-76.

MOREIRA DE SÁ, Artur. De re erasmiana: aspectos do erasmismo na cultura portuguesa do século XVI. Braga: Publicações da Faculdade de Filosofia, 1977.

MUSSER, Ricarda. Building up Networks of Knowledge: Printing and Collecting Books in the Age of Humanism in the University City of Coimbra. In: BerbARA, Maria; ENENKEL, Karl A. E. (eds.). Portuguese Humanism and the Republic of Letters. Leiden: Brill, 2012, p. 113-127.

PETTEGREE, Andrew. The Book in the Renaissance. New Haven: Yale University Press, 2010.

PHILLIPS, Mark Salber. Reconsiderations on History and Antiquarianism: Arnaldo Momigliano and the Historiography of Eighteenth-Century Britain. Journal of the History of Ideas, v. 57, n. 2, p. 297-316, 1996.

RESENDE, André de. Aegidius Scallabitanus. In: PEREIRA, Virgínia Soares. Aegidius Scallabitanus: um diálogo sobre Fr. Gil de Santarém. Lisboa: Fundação Calouste Gulbenkian, 2000, p. 277-695.

Antiguidades da Lusitânia. Introdução, tradução e comentário de R. M. Rosado Fernandes. Lisboa: Fundação Calouste Gulbenkian, 1996;

. Carta a Bartolomeu de Quevedo. Tradução, introdução e notas de Virgínia Soares Pereira. Coimbra: Instituto Nacional de Investigação Científica/Centro de Estudos Clássicos e Humanísticos da Universidade de Coimbra, 1988 [1567].

. História da Antiguidade da Cidade de Évora. In: Obras portuguesas de André de Resende. Lisboa: Livraria Sá da Costa, 1963 [1553], p. 1-69.

. Oração de sapiência (Oratio pro rostris). Tradução de Miguel Pinto de Meneses, introdução e notas de A. Moreira de Sá. Lisboa: Instituto de Alta Cultura, 1956 [1534].

STENHOUSE, William. Reading Inscriptions and Writing Ancient History: Historical Scholarship in the Late Renaissance. London: Institute of Classical Studies, 2005.

TARRÍO, Ana María Sanchez. Pedro Nunes e os humanistas do seu tempo. In: NASCIMENTO, Aires A. (org.). Pedro Nunes e Damião de Góis: dois rostos do humanismo português - atas dos colóquios no $\mathrm{V}$ centenário do nascimento. Lisboa: Guimarães, 2002, p. 59-93.

VINE, Angus. In Defiance of Time: Antiquarian Writing in Early Modern Britain. Oxford: Oxford University Press, 2010. 
WOMERSLEY, David. Against the Teleology of Technique. In: KEWES, Paulina (org.). The Uses of History in Early Modern England. San Marino: Huntington Library, 2006, p. 91-104.

WOOD, Christopher S. Early Archaeology and the Book Tradition. The Case of Peutinger's Romanae uetustatis fragmenta (1505). Journal of Medieval and Early Modern Studies, v. 28, n.1, Winter 1998, p. 83-118. . Notation of visual information in the earliest archaeological scholarship. Word \& Image, v. 17, n. 1/2, p. 94-118, 2001. 